\title{
The Implementation of the Cluster Approach in the Regional System of Vocational Education
}

\author{
Albina R. Shaidullina ${ }^{1}$, Alfiya M. Ishmuradova ${ }^{2}$, Elvira V. Maksimova ${ }^{2}$, Olga G. Yevgrafova ${ }^{2}$, Farida V. \\ Derdizova $^{2}$, Pavel A. Baklanov ${ }^{2} \&$ Angelina O. Bagateeva $^{2}$ \\ ${ }^{1}$ Almetyevsk State Oil Institute, Almetyevsk, Russia \\ ${ }^{2}$ Kazan (Volga region) Federal University, Kazan, Russia \\ Correspondence: Albina R. Shaidullina, Foreign Languages' Department, Almetyevsk State Oil Institute, \\ Almetyevsk, 423450, Russia. E-mail: albina-plus@mail.ru
}

Received: December 29, 2014 Accepted: January 22, 2015 Online Published: February 11, 2015

doi:10.5539/res.v7n4p66 URL: http://dx.doi.org/10.5539/res.v7n4p66

\begin{abstract}
The relevance of the problem stems from the fact that the implementation of the cluster approach in the regional system of vocational education aimed at the maintenance and development of joint potential opportunities of industrial and educational spheres, which create prospects for progressive development of the Tatarstan Republic. This article aims to identify the features of the cluster approach in the regional system of vocational training that focus on strengthening the relationship network between the cluster members in order to facilitate access to new industrial and educational technologies, to share knowledge and fixed-capital assets, to accelerate learning processes due to continuity and integration processes in a single integrated regional educational-industrial complex. The article stuff is valuable for managers of vocational training institutions and representatives of the industrial sector in order to prepare specialists meeting the requirements of modern production.
\end{abstract}

Keywords: cluster approach, educational cluster, regional system of vocational education, educational-industrial complexes

\section{Introduction}

In contemporary world the importance of education as the most important factor in the formation of a new quality of economy and society is increasing together with the growth of human capital assets. The market economy raises the problems of transition to a whole new level of professional training (Anischenko, 2002; Shaidullina, 2012; Telegina, Galimova \& Masalimova, 2015). Heads of organizations want to have competitive specialists, who are mobile and able to solve professional problems in unusual situations. In this regard the system of lifelong vocational education is a perspective direction of training which should be focused on the innovative type of society development through the effective use of scientific knowledge and new "breakthrough" information technologies providing the opportunity to reduce consumption of resources, to ensure the sustainable development of civilization, to prepare millions of people to the professional activities in the condition of information society (Belyaeva, 2001; Vinogradov, 2001; Volov, 2007; Masalimova \& Sabirova, 2014).

Strategically clustering is aimed at more effective use of knowledge and thus increasing the competitiveness of production and the creation of new cooperation networks within the clusters.

Cluster policy is an important part of the state economic policy. It includes a system of interrelated actions of federal and regional authorities, local authorities, business organizations, research and educational institutions, non-governmental organizations which aimed to support initiatives for the creation and development of their co-operation and integration, creating the conditions for it. It is necessary to stimulate the creation of different types so that clusters become one of the state policy priorities of the regional development. The important elements of the cluster policy must be the development and implementation of federal and regional programs promoting the organization and functioning of the cluster formations, the development of public-private partnership in this direction (Fayzullina \& Mukhametzyanova-Duggal, 2015).

The cluster approach is not only updates the integration of educational institutions into a single system connected by relationships of preparation of competitive and sought-after experts, but also indicates the preferred direction of the educational system, namely, its integration and adjustment of standards, which connect the outputs of 
some educational institutions (a lower order, for example, schools) with others (a higher order, such as colleges and universities) (Shaidullina \& Fatkhullina, 2013; Fayzullina \& Saglam, 2014; Mrathuzina et al, 2015).

The purpose of the education cluster is to improve the quality of the vocational training which meets current and future needs of the social partners in highly qualified specialists. There are the following main tasks within the noted goal:

- Social partners collective planning of the cooperation direction in the sphere of labor force and specialists training;

- Ensuring financial resources for of specialists and labor force training real projects;

- Ensuring the participation of employers in the programs of educational institutions development;

- Improving the quality of special subjects and practical training;

- Sustainable development of material-technical base of educational institutions on the long term basis;

- Introduction advanced techniques and methods of work organization into the vocational training of students;

- Increase the students' motivation for learning, development of profession (specialty) acquisition;

- Active career guidance of students (Zhivokorentseva, 2005; Manushin \& Dobryakov, 2007; Sazonova, 2007).

\section{Literature Review}

The term "cluster" is the most popular at present. Nevertheless, analysis of specialized literature has shown the absence of a unique approach to this concept. For example, D. A. Yalov gives the following definition of "cluster": this is a network of suppliers, manufacturers, consumers, elements of industrial infrastructure, research institutes interconnected in the creation of surplus value (Yalov, 2003).

V. P. Tretyak distinguishes clusters and enterprise networks. In his opinion, the term "network" refers to a group of medium-sized firms that cooperate to achieve common goals-complementing each other and specializing in order to overcome common problems, to achieve collective efficiency and to capture new markets, and the term "cluster", in his opinion, indicates a sectoral and geographical concentration of enterprises that produce and sell a range of related or complementary products by joint efforts (Tretyak, 2002).

According to the theory of Michael Porter, a cluster is a group of geographically adjacent, interconnected companies (suppliers, manufacturers and others) and associated organizations (educational institutions, general government, infrastructure companies) operating in a certain area and complementary to each other. Michael Porter believes that the country's competitiveness should be viewed through the prism of international competitiveness not its individual firms but clusters which are the union of firms in different industries. Thus the ability of clusters to use effectively internal resources has the principle concern. As a part of the study the researcher has analyzed the competitive opportunities of over 100 branches in ten countries. It turned out that the most competitive multinational companies do not usually scattered haphazardly across countries and tend to be concentrated in one country, and sometimes even in the same region of the country. This is explained by the fact that one or more companies, achieving international competitiveness, extend its positive influence on the immediate environment: suppliers, customers and competitors. And the success of the environment, in turn, has an impact on the further growth of the competitiveness of the company. As the result, the "cluster" is forming - that means a community of companies in closely related industries, mutually contributing to the growth of competitiveness of each other. After the first one the new clusters are often formed and the international competitiveness of the country as a whole increases (Porter, 1993).

A. A. Migranyan believes that the cluster is a concentration of the most effective and interrelated economic activities, that is a set of interrelated groups, successfully competing firms which form the "golden section" (in the western interpretation it is the "diamond" of the entire state economic system and provide competitive positions at the sectoral, national and international markets (Migranyan, 2002).

From the viewpoint of T. V. Tsikhan, cluster is a community of companies in closely related industries, mutually contributing to the growth of competitiveness of each other (Tsikhan, 2003). However, the community-it is not only a multitude connected by precisely synergistic relationships which helps to reduce transaction costs, but also to determine the properties of the cluster as a system that is different from the properties of multiple organizations within the cluster beyond specified links. Therefore, T. V. Tsikhan's position is quite fair that clusters serve as points of growth of the domestic market for the whole state economy. This idea comes from the corollary of the second thermodynamics law that the ordering of the system can be increased only by entropy enlargement in the environment. That is by organizing into a more well-ordered system (cluster) organizations at 
the same time weaken the environment, being a point of growth to which other organizations begin to "dock". Clusters can be represented by regionally limited economic formations, vertical production chains and industries (Tsikhan, 2003).

The cluster is an integration mechanism for intensive development of its constituent organizations and their social partnership (Mukhametzyanova \& Pugacheva, 2007).

\section{Results}

There can be roughly distinguished purely educational clusters, for example, such complexes as "school-vocational school—college" and mixed clusters, for example, various types of research - production — educational complexes. By way of foundations there can be distinguished the following characteristics, on the combination of which the creation of the cluster is based:

- Regional: Beginning from the city or the subject of the Russian Federation (e.g., educational clusters in the Republic of Tatarstan, Krasnoyarsk, etc.) to the country (clusters in the Republic of Kazakhstan, etc.);

- Horizontal: Several schools in one level may be in the same cluster;

- Vertical: Educational institutions at various levels united into in a cluster, for example, vocational school — college - university;

- Lateral: Diversified and split-level educational institutions, enterprises and organizations united into a cluster;

- Industrial: A set of educational institutions, enterprises and organizations of the same sphere;

- Focus: Educational institutions concentrated around a single enterprise, research institute;

- Qualitative: A set of institutions, enterprises and organizations united in order to create and introduce innovations (Mukhametzyanova \& Pugacheva, 2007).

As being the specific models of clusters can be called colleges, university complexes, service centers, industrial parks and others. For example, in the Republic of Tatarstan there have been created clusters which include basic enterprises, research institutes, universities, colleges and vocational schools.

The advantages of clusters lie in the fact that: firstly, internal resources are used in clusters effectively: human, scientific and information potential, finance, infrastructure; secondly, the quality of training in clusters is higher, graduates are more in demand in the labor market and meet the requirements of production much better; thirdly, educational technologies, training equipment, training workshops and other equipment are used more efficiently; fourthly, the training time is reducing by integrating learning content, implementation of the continuity principle in the objectives, content, methods, forms, training aids; fifthly, principles of perspective and humanization of education are realized. Clustering on various grounds forms not spontaneous concentration of scientific, technological and educational innovations variety, but a certain system of new knowledge, industrial and educational technologies dissemination.

However, there is a number of problems of theoretical and practical plans for the creation and development of educational clusters. Is it permissible to reform the education system based solely on considerations of economic expediency? What are the specific short, medium and long-term objectives of cluster development? How important is the education cluster in the state economy? What models of clusters does Russia need? Evidently, it is impossible to talk about the effectiveness of the cluster approach to the vocational education reform without deciding these problems.

At the same time there is a risk of loss the autonomy (ability to self-line behavior in the market of educational services, to the independent development of new content, technologies, training, etc.) of educational institutions included in the cluster, and the cluster transformation into the education cartel. Therefore, a necessary condition for the creation of educational cluster is the maintenance of competitive relationship between the participants in the educational market. But perhaps the most important in the cluster approach to vocational education is the creation of a special form of innovation - "aggregate innovative product"- the graduate of a qualitatively new type who can meet the requirements of a modern market, high-tech industry.

The clustering on various grounds forms not spontaneous concentration of divers scientific, technological and educational innovations but a certain system of new knowledge, industrial and educational technologies dissemination. In this case the most important condition for the effective transformation of scientific, technical, technological and pedagogical innovations in production, thus, creating competitive advantages is the formation of stable network links between all cluster members. For example, in the Republic of Tatarstan as the prerequisites of such links serve: 
- The agreement on the state-corporate partnership in the field of qualified personnel training within the education cluster (it is concluded between the Government, represented by sectoral ministry, the Ministry of Education and Science of the Republic of Tatarstan, base enterprises, head university);

- The agreement on the personnel training between the customer and the educational institution;

- The contract between the student and the employer;

- The charter of an autonomous educational institution of secondary vocational education "vocational college";

- The procedure for the formation of state-corporate orders for personnel training (founder's tasks);

- Methods of normative budgetary financing of primary and secondary vocational education.

The creation and development of clusters should become one of the key areas of economic development and diversification not only the Russian Federation as a whole, but also the Republic of Tatarstan in particular in condition of market economy.

Nowadays in the Republic of Tatarstan there have been signed 14 agreements on state-corporate partnership in the field of training within the educational clusters such as a cluster of high technology, an engineering cluster, a cluster of power industry, a light industry cluster, a cluster of oil-chemistry and oil refining, a cluster of oil production and transportation, agro-industrial cluster, and others. (Table 1).

Table 1. Industry clusters of the Republic of Tatarstan

\begin{tabular}{lll}
\hline No. & Industry Education Cluster & Supervising Ministry \\
\hline 1 & Production and transportation of oil and gas. & \\
& Oil-chemistry and oil refining & Ministry of Economic and Industry \\
2 & High-Tech & \\
3 & Power industry & \\
4 & Mechanical Engineering & \\
5 & Aircraft engineering & Ministry of Agriculture and Food \\
6 & Light industry & Ministry of Construction, Architecture, Housing \\
7 & Agroindustrial complex & and Public Utilities \\
8 & Construction, architecture, housing and public utilities \\
& & Ministry of Trade and Foreign Economic \\
9 & Commercial and service industry & Cooperation \\
& & Ministry of Transportation \\
10 & Transport and road facilities & Ministry of Communication and Information \\
11 & Informatization and communication & Ministry of Education and Science \\
12 & Education & Ministry of Health \\
13 & Health & Ministry of Culture \\
14 & Culture and art & \\
\hline
\end{tabular}

The following members enter the education cluster of high technology of the Tatarstan Republic:

- Research institutions: OJSC "NPO "State Institute of Applied Optics"; SRI Turbocompressor named after Shnepp, ICL—KME SC; TatNIIneftemash; FSUE "Kazan Research Institute of Radio Electronics”; FSI "Federal Center for Toxicological, Radiation and Biological Safety";

- Institutions of higher education: Kazan (Volga region) Federal University; Kazan National Research Technical University named after A. N. Tupolev-KAI (KNRTU-KAI).

- Institutions of secondary vocational education: Kazan Electro College of telecommunication, Almetyevsk Polytechnic College, Bugulma Engineering College;

- Vocational schools: No. 4, 15, 32, 50, 59, 64, 65, 68 and the professional college No. 51. 
Status of the head university in the machine manufacturing cluster received the Kazan National Research Technical University named after A. N. Tupolev-KAI (KNRTU-KAI). It also includes Kama State Engineering and Economics Academy and Almetyevsk State Oil Institute, Kazan Aviation College. Among basic enterprises there are: JSC «Kazan plant "Elektropribor”, JSC “ElAZ”, JSC “Alnas”, JSC “Radiopribor”, JSC “Elecon”, JSC "Innovative-industrial techno park "Vostok" and others.

The Energy cluster of the Tatarstan Republic includes: SEI HPE "Kazan State Power Engineering University", basic enterprises: JSC "Tatenergo", "Grid Company", "Generating Company", CJSC "ROC Tatenergo", plant "Elektropribor". The secondary vocational training in the cluster energy is carried out in Kazan Energy College, the primary vocational training is carried out in Nizhnekamsk Technology College, vocational schools: No. 4, 18, $34,39,50,57,62,64,65,68,104,122$.

The head institution in the cluster of light industry, as well as oil-chemistry and oil refining is the Kazan State Technological University (KSTU) which coordinates the process of education with such companies as JSC "Nizhnekamskneftekhim", JSC "Kazankompressormash", JSC "Kazanorgsintez", JSC "Nizhnekamskshina" and others in the field of oil-chemistry and oil refining; JSC "Adonis", JSC "Melita", JSC "Shoe Factory "Spartak" and others in the field of light industry.

The structure of educational cluster on oil and gas production and transportation of the Tatarstan Republic includes:

- Industrial enterprises: JSC “Tatneft”, JSC “Gasprom Transgas Kazan “, etc .;

- Research institutions: TatNIPIneft, TatNIIneftemash;

- Establishments of staff training and retraining: Almetyevsk zone center of interbranch regional center of professional retraining and advanced training of managers and specialists of RT at Almetyevsk State Oil Institute; Private educational institution "Staff Training Center-Tatneft";

- Institution of higher education - Almetyevsk State Oil Institute;

- Institutions of secondary vocational education: Almetyevsk Polytechnic College; Leninogorsk Oil College, etc.;

- Vocational schools: Almetyevsky professional lyceum No. 65; Leninogorsk vocational school number 14 and others.

It is well known that in all regions of the country there are not enough skilled workers, whereas, there is a surplus of specialists with higher education diplomas, since due to the lack, and sometimes the absence of links with the industrial and scientific sectors the educational system is not able to solve the problems existing in the labor market:

- Training highly skilled workers (4-6-th categories);

- Training competitive professionals, capable to look after modern equipment and develop existing production.

In such conditions when professional education cannot adequately carry out this training, the following situation appears:

- Vocational education quality reduce and its irrelevance;

- Inexpedience of investments in education;

- Growth deficit of demanded labor force (Mukhametzyanova and Pugacheva, 2007).

Industrial cluster-oriented policy stimulates the emergence of new competitive advantages by focusing on education and science and leads to the creation of a particular form of innovation-"aggregate innovation product".

\section{Discussions}

The cluster approach determines priorities of education system development, and the creation and development of clusters is also a prerequisite for integration processes, both within education and in the chain of "science-education-production."

Under these conditions, the cluster approach can be considered as one of new management technologies of society socio-economic development, including education. The cluster approach is capable of changing the national education policy in the most fundamental way. In accordance with the efforts of officials in the educational sphere should be directed not on the support of individual educational institutions and educational subsystems but on the development of relationship between schools and vocational education institutions, between enterprises employing personnel and educational institutions, between schools themselves and 
executive bodies etc.

An important feature of the cluster is its innovative orientation. There are the following basic forms of state innovation policy: direct budget support of vocational training of workers and specialists within educational clusters; indirect support by tax policy and using administrative regulation; investments in education. In addition, the vocational education institution has access to modern production technologies.

The special feature of integration in the regional system of vocational education lies in the implement of the cluster model aimed at the preservation and development of joint potential industrial and educational spheres creating prospects for progressive development of the Republic of Tatarstan in terms of awareness of its importance in the ownership and active reform activities for sustainable development the republic's economy. The main tasks of the cluster policy in the region are characterized by the fact that main attention is focused at strengthening the relationship network between the cluster members in order to facilitate access to new industrial and educational technologies, share knowledge and fixed-capital assets, accelerate learning processes due to continuity and integration processes in a single integrated regional educational-industrial complex.

\section{Conclusion}

The special feature of integration in the regional system of vocational education lies in the implement of the cluster approach aimed at the preservation and development of joint potential industrial and educational spheres creating prospects for progressive development of the Republic of Tatarstan in terms of awareness of its importance in the ownership and active reform activities for sustainable development the republic's economy. The main tasks of the cluster policy in the region are characterized by the fact that main attention is focused at strengthening the relationship network between the cluster members in order to facilitate access to new industrial and educational technologies, share knowledge and fixed-capital assets, accelerate learning processes due to continuity and integration processes in a single integrated regional educational-industrial complex. In the education cluster pupils and students are given the opportunity for employment according to the specified profession and qualification; a primary salary is guaranteed at the level of not less than the minimum consumer budget; certified and paid work positions for manufacturing practice are provided; base enterprise's scholarships are paid to students; assignment money are performed to young specialists; decision of housing problems, etc.

\section{References}

Anischenko, V. A. (2002). Integration of science, education and production. Specialist, $8,18$.

Belyaeva, A. P. (2001). Development of vocational education. Pedagogy, 8, 3-8.

Fayzullina, A. R., \& Mukhametzyanova-Duggal, R. M. (2015). Multi-Confessional Societies in Russia and India: Models of Relations between the State and Religious Associations. Review of European Studies, 7(1), 12-17.

Fayzullina, A. R., \& Saglam, F. A. (2014). Methods and forms of organization of training activities on the lessons of history. History teaching in school, 9, 45-50.

Manushin, E., \& Dobryakov, A. (2007). Model training elite specialists. Higher education in Russia, 8, 3-16.

Masalimova, A. R., \& Sabirova, L. L. (2014). Multi-dimentional classification of types and forms of corporate education. American Journal of Applied Sciences, 11(7), 1054-1058. http://dx.doi.org/10.3844/ajassp.2014.1054.1058

Migranyan, A. A. (2002). Theoretical Aspects of competitive clusters in countries with economies in transition. Retrieved from http://subcontract.ru/Dokum/DokumShow_DokumID_171.html

Mrathuzina, G. F., Fayzullina, A. R., \& Saglam, F. A. (2015). Substantive, Methodological and Organizational Discourse in Oriental History Learning at School and University. Review of European Studies, 7(1), 57-62.

Mukhametzyanova, G. V., \& Pugacheva, N. B. (2007). The cluster approach to the management of vocational education (p. 144). Kazan: PPIs RW.

Porter, M. (1993). International competition. Moscow: International Relations.

Sazonova, Z. S. (2007). Integration of education, science and industry as a methodological basis of preparation of the modern engineer (p. 487). Moscow: Publishing House of MADI (STU).

Shaidullina, A. R. (2012). Regional Experience of Integration in System Vocational School-High School-Manufacture. Memoirs of Almetyevsk State Oil Institute, 2, 306-312.

Shaidullina, A. R., \& Fatkhullina, R. A. (2013). Education system of innovative entrepreneurship in continuing 
professional education. Theory and practice of modern vocational education, 1, 134-138.

Telegina, N. V., Galimova, E. G., \& Masalimova, A. R. (2015). The Structure and Content of the Model of Pedagogical Conditions Binary Approach to Optimization of Control and Diagnostic Functions in Teaching "General pedagogy" to Students. Asian Social Science, 11(1), 364-368.

Tretyak. V. P. (2002). Clusters of enterprises: The establishment and effective functioning. Retrieved from http://subcontract.ru/Dokum/DokumShow_DokumID_133.html

Tsikhan, T. V. (2003). Cluster Theory of Economic Development. The theory and practice of management, 5, 27.

Vinogradov, B. A. (2001). Scientific, scientific-technical and innovation policy in the education system of the Russian Federation. Economics of Education, 4, 7-20.

Volov, V. T. (2007). Innovative principles of the education system. Pedagogy, 7, 108-114.

Yalov, D. A. (2003). The cluster approach as a technology management of regional economic development. Retrieved from http://subcontract.ru/Dokum/DokumShow_DokumID_17.html

Zhivokorentseva, T. V. (2005). Integration of educational content in pedagogical college as a problem of collective practice-oriented research (p. 256). Saint Petersburg.

\section{Copyrights}

Copyright for this article is retained by the author(s), with first publication rights granted to the journal. This is an open-access article distributed under the terms and conditions of the Creative Commons Attribution license (http://creativecommons.org/licenses/by/3.0/). 